\title{
Errata - Avaliação dos testes clínicos e da ressonância magnética para lesões meniscais do joelho: correlacão com a videoartroscopia
}

Leonardo Côrtes Antunes ${ }^{1}$ José Marcio Gonçalves de Souza ${ }^{1}$ Nelson Baisi Cerqueira ${ }^{1}$ Cleiton Dahmer ${ }^{1}$ Breno Almeida de Pinho Tavares ${ }^{1}$ Ângelo José Nacif de Faria ${ }^{2}$

${ }^{1}$ Hospital Ortopédico de Belo Horizonte, Grupo de Cirurgia e Reabilitação do Joelho, Belo Horizonte, MG, Brasil

${ }^{2}$ Hospital São Francisco de Assis de Belo Horizonte, Ortopedia e

Traumatologia, Belo Horizonte, MG, Brasil

Rev Bras Ortop 2020;55:130.

ERRATA
Rio de Janeiro, 05 de Fevereiro de 2020

Caros leitores,

No artigo Avaliação dos testes clínicos e da ressonância magnética para lesões meniscais do joelho: correlacão com a videoartroscopia (Rev Bras Ortop 2017;52(05): 582-588. DOI: http://dx.doi.org/10.1016/j.rbo.2016.09.009.), publicado online na Revista Brasileira Ortopedia em Setembro de 2017:

Onde se lê:

José Nacif de Faria

Leia-se:

José Nascif de Faria 